\title{
A New UPLC-qTOF Approach for Elucidating Furan and 2-Methylfuran Metabolites in Human Urine Samples after Coffee Consumption
}

\author{
Simone Stegmüller ${ }^{1}$, Nadine Beißmann ${ }^{1}$, Jonathan Isaak Kremer ${ }^{1}{ }^{(0)}$, Denise Mehl ${ }^{2}$, \\ Christian Baumann ${ }^{2}$ and Elke Richling ${ }^{1, *(D)}$ \\ 1 Technische Universität Kaiserslautern, Department of Chemistry, Division of Food Chemistry and \\ Toxicology, Erwin-Schrödinger-Str. 52, 67663 Kaiserslautern, Germany; stegmueller@chemie.uni-kl.de (S.S.); \\ beissmann@chemie.uni-kl.de (N.B.); kremer@chemie.uni-kl.de (J.I.K.) \\ 2 AB SCIEX Germany GmbH, 64293 Darmstadt, Germany; denise.mehl@sciex.com (D.M.); \\ Christian.baumann@sciex.com (C.B.) \\ * Correspondence: richling@chemie.uni-kl.de; Tel./Fax.: +0049-631-205-4061 (ext. 3085)
}

Academic Editor: Thomas Letzel Received: 6 October 2020; Accepted: 30 October 2020; Published: 3 November 2020

\begin{abstract}
We have investigated urine samples after coffee consumption using targeted and untargeted approaches to identify furan and 2-methylfuran metabolites in urine samples by UPLC-qToF. The aim was to establish a fast, robust, and time-saving method involving ultra-performance liquid chromatography-quantitative time-of-flight tandem mass spectrometry (UPLC-qToF-MS/MS). The developed method detected previously reported metabolites, such as Lys-BDA, and others that had not been previously identified, or only detected in animal or in vitro studies. The developed UPLC-qToF method detected previously reported metabolites, such as lysine-cis-2-butene-1,4-dial (Lys-BDA) adducts, and others that had not been previously identified, or only detected in animal and in vitro studies. In sum, the UPLC-qToF approach provides additional information that may be valuable in future human or animal intervention studies.
\end{abstract}

Keywords: furan; 2-methylfuran; UPLC-qToF; untargeted analysis; urinary metabolites

\section{Introduction}

Furan and 2-methylfuran (2-MF) are colorless liquids that are very slightly soluble in water. Furan has been classified by the International Agency for Research on Cancer (IARC) as a possible carcinogen (class 2B) [1,2].

Furan is mainly found in coffee and jarred food. Therefore, in Europe adults and infants reportedly have the highest furan intakes, and 95\% of the adults' daily intake is reportedly through coffee, as the mean level of furan in whole roasted coffee beans is $4.58 \mathrm{mg} / \mathrm{kg}$ [3]. The furan content of coffee beverages depends on various factors, such as roasting temperature and duration, preparation method, and use of instant or ground coffee. Coffee beverages prepared by an espresso machine have higher furan levels than coffee prepared, from the same ground coffee, by a drip coffee maker (open system) $[4,5]$. The 2-MF content has been found to be ca. six-fold higher than the furan content and is the main furan derivative identified in coffee [6].

Furan and 2-MF are formed in food via various pathways and precursors, such as ascorbic acid, amino acids, carbohydrates, unsaturated fatty acids, and carotenoids. Furan formation also occurs during the thermal decomposition of serine and cysteine [7-9]. Furthermore, 2-MF can be formed from amino acid and $\alpha, \beta$-unsaturated aldehydes [9].

There is no experimental evidence of furan genotoxicity in peripheral blood or bone marrow cells but chromosomal aberrations linked to its exposure have been detected in rat splenocytes, 
indicating that it may damage DNA in the liver within 28 days [10]. Moreover, in a two-year study administration by gavage reportedly increased incidences of mononuclear cell leukemia, cholangiocarcinoma, and hepatocellular neoplasms in livers of male and female rats [11]. However, hepatotoxicity and carcinogenicity depend on doses and time [12], and for hepatocarcinogenicity furan must be activated to cis-2-butene-1,4-dial (BDA) by cytochrome P450 2E1 [13].

Bioactivation also seems to be necessary for 2-MF activity [14]. In hepatic and pulmonary microsomal systems acetylacrolein (AcA; (2Z)-oxopent-2-enal) has been identified as a possible reactive intermediate of 2-MF [15]. Apoptotic hepatocytes, abnormally pigmented Kupffer cells, and inflammatory infiltration have been observed in rats after 2-MF intake [16], and a No Observed Adverse Effect Level (NOAEL) of $0.4 \mathrm{mg} / \mathrm{kg}$ bodyweight (BW) per day has been calculated for it [6].

Due to the high reactivity of the main metabolites, BDA and AcA, of furan and 2-MF, they can react in the human body with diverse biomolecules, such as amino acids, glutathione, and nucleosides. Thus, the aims of this study were to identify adducts of BDA and AcA in the urine of participants who had previously consumed a coffee brew and establish excretion kinetics for identified metabolites. Since the examination and evaluation of the collected urine samples with a targeted approach using conventional high-performance liquid chromatography-tandem mass spectrometry (HPLC-MS/MS) analysis would be very time-consuming and costly, a new approach using ultra-performance LC-quantitative time-of-flight MS/MS was applied. This approach requires less laborious sample preparation, and provides exact masses of analytes, with the associated possibility of database searches, recording all MS/MS spectra over the set mass range, as well as a significant reduction in measuring time. The urine samples tested had already been examined in a previous study with a targeted approach $[17,18]$. The results obtained in the study presented here are intended to complement these data by identifying previously unknown metabolites and show whether the new approach can provide at least as good results as the targeted approach.

\section{Results and Discussion}

The main objective of the study was to determine the effectiveness of the untargeted UPLC-qToF-MS/MS approach for identifying known and unknown metabolites in human urine without complex sample preparation and the possibility of using it to complement or even replace targeted UPLC-MS/MS analyses. A major advantage of the method is that a large amount of data is collected for each sample and can be retrospectively used to address various questions.

The specific aims of this study were to identify furan and 2-MF in metabolites in samples of urine collected from participants $36 \mathrm{~h}$ after they had consumed a bolus of coffee brew. Details of the study design have been previously published [17]. Due to limitations in time to use the qToF apparatus, only urine samples from five of the 10 participants were used in the UPLC-qToF-MS/MS measurements. The results were compared with results from previous targeted investigations. An overview of the identified metabolites of furan and 2-methylfuran are given in Tables 1 and 2. 
Table 1. Exact mass, found mass, and retention time of each furan and 2-methylfuran metabolite identified by UPLC-qToF-MS/MS, and matrices in which they have been previously found (with supporting references). Meanings of the abbreviated metabolites' names are given in the text or present the meanings in a footnote.

\begin{tabular}{|c|c|c|c|c|c|}
\hline Metabolite & Chemical Formula & $\begin{array}{l}\text { Exact Mass } \\
\text { (Da) }\end{array}$ & Found at $m / z$ & Retention Time (min) & $\begin{array}{l}\text { Matrices where Previously } \\
\text { Found and References }\end{array}$ \\
\hline GSH-BDA & $\mathrm{C}_{14} \mathrm{H}_{17} \mathrm{~N}_{3} \mathrm{O}_{6} \mathrm{~S}$ & 355.083809 & $356.1000[\mathrm{M}+\mathrm{H}]^{+}$ & 7.63 & human urine [19-21], urine, bile, and hepatocytes of rats [22] \\
\hline Lys-BDA & $\mathrm{C}_{10} \mathrm{H}_{16} \mathrm{~N}_{2} \mathrm{O}_{3}$ & 212.11609 & $213.1232[\mathrm{M}+\mathrm{H}]^{+}$ & 2.27 & human urine $[20,23]$ \\
\hline AcLys-BDA & $\mathrm{C}_{12} \mathrm{H}_{18} \mathrm{~N}_{2} \mathrm{O}_{4}$ & 254.12666 & $255.1345[\mathrm{M}+\mathrm{H}]^{+}$ & 4.36 & human urine $[20,23]$; rat urine $[19,23]$ \\
\hline AcCys-BDA-Lys & $\mathrm{C}_{15} \mathrm{H}_{23} \mathrm{~N}_{3} \mathrm{O}_{5} \mathrm{~S}$ & 357.13584 & $356.1167[\mathrm{M}-\mathrm{H}]^{-}$ & 7.58 & human urine and rat urine [23]; rat urine $[23,24]$; rat hepatocytes [22] \\
\hline AcCys-BDA-AcLys & $\mathrm{C}_{17} \mathrm{H}_{25} \mathrm{~N}_{3} \mathrm{O}_{6} \mathrm{~S}$ & 399.14641 & $400.1471[\mathrm{M}+\mathrm{H}]^{+}$ & 1.24 & urine, bile, and hepatocytes of rats $[19,22-24]$ \\
\hline AcCys (SO)-BDA-AcLys & $\mathrm{C}_{17} \mathrm{H}_{25} \mathrm{~N}_{3} \mathrm{O}_{7} \mathrm{~S}$ & 415.14132 & $416.1484[\mathrm{M}+\mathrm{H}]^{+}$ & 4.46 & rat urine $[19,23,24]$ \\
\hline methanethiol-BDA-Glu & $\mathrm{C}_{10} \mathrm{H}_{13} \mathrm{NO}_{4} \mathrm{~S}$ & 243.05653 & $244.0793[\mathrm{M}+\mathrm{H}]^{+}$ & 1.05 & rat urine $[19,24]$ \\
\hline GSH-BDA-Lys & $\mathrm{C}_{20} \mathrm{H}_{31} \mathrm{~N}_{5} \mathrm{O}_{8} \mathrm{~S}$ & 501.18933 & $502.1740[\mathrm{M}+\mathrm{H}]^{+}$ & 7.57 & rat urine [25]; rat hepatocytes $[19,22]$ \\
\hline GSH-BDA-Gln & $\mathrm{C}_{19} \mathrm{H}_{27} \mathrm{~N}_{5} \mathrm{O}_{9} \mathrm{~S}$ & 501.15295 & $500.1478[\mathrm{M}-\mathrm{H}]^{-}$ & 7.59 & rat urine [25]; rat hepatocytes $[19,22]$ \\
\hline GSH-BDA-AcLys & $\mathrm{C}_{22} \mathrm{H}_{33} \mathrm{~N}_{5} \mathrm{O}_{9} \mathrm{~S}$ & 543.19990 & $544.2036[\mathrm{M}+\mathrm{H}]^{+}$ & 7.59 & rat hepatocytes $[19,22]$ \\
\hline GSH-BDA-Glu & $\mathrm{C}_{19} \mathrm{H}_{26} \mathrm{~N}_{4} \mathrm{O}_{10} \mathrm{~S}$ & 502.13696 & $503.1497[\mathrm{M}+\mathrm{H}]^{+}$ & 1.47 & rat bile $[19,22,26]$ \\
\hline Cys-BDA-GSH & $\mathrm{C}_{17} \mathrm{H}_{24} \mathrm{~N}_{4} \mathrm{O}_{8} \mathrm{~S}_{2}$ & 476.10356 & $475.0941[\mathrm{M}-\mathrm{H}]^{-}$ & 7.68 & rat bile $[19,26]$ \\
\hline CysGyl-BDA-GSH & $\mathrm{C}_{19} \mathrm{H}_{27} \mathrm{~N}_{5} \mathrm{O}_{9} \mathrm{~S}_{2}$ & 533.12502 & $532.1480[\mathrm{M}-\mathrm{H}]^{-}$ & 7.60 & rat bile $[19,26]$ \\
\hline BDA-Lys-BDA & $\mathrm{C}_{14} \mathrm{H}_{18} \mathrm{~N}_{2} \mathrm{O}_{4}$ & 278.12666 & $277.1187[\mathrm{M}-\mathrm{H}]^{-}$ & 7.57 & not previously reported, but postulated \\
\hline Cys-BDA & $\mathrm{C}_{7} \mathrm{H}_{9} \mathrm{NO}_{3} \mathrm{~S}$ & 187.03031 & $188.0384[\mathrm{M}+\mathrm{H}]^{+}$ & 3.32 & not yet reported in the literature, only theoretical \\
\hline
\end{tabular}

Table 2. Exact mass, found mass, and retention time of each furan and 2-methylfuran metabolite identified by UPLC-qToF-MS/MS, and matrices in which they have been previously found (with supporting references). Meanings of the abbreviated metabolites' names are given in the text or present the meanings in a footnote.

\begin{tabular}{cccccc}
\hline Metabolite & Chemical Formula & $\begin{array}{c}\text { Exact Mass } \\
\text { (Da) }\end{array}$ & Found at $m / z$ & Retention Time (min) & Previously Detected in (References) \\
\hline AcCys-BDA & $\mathrm{C}_{9} \mathrm{H}_{11} \mathrm{NO}_{5} \mathrm{~S}$ & 245.25234 & $246.0431[\mathrm{M}+\mathrm{H}]^{+}$ & 1.46 & not previously reported, but postulated \\
Lys-AcA & $\mathrm{C}_{11} \mathrm{H}_{20} \mathrm{~N}_{2} \mathrm{O}_{3}$ & 228.14739 & $227.1386[\mathrm{M}-\mathrm{H}]^{-}$ & 3.87 & not previously reported, but postulated \\
AcLys-AcA & $\mathrm{C}_{13} \mathrm{H}_{20} \mathrm{~N}_{2} \mathrm{O}_{4}$ & 268.30890 & $267.1258[\mathrm{M}-\mathrm{H}]^{-}$ & 7.65 & not previously reported, but postulated \\
AcCys-AcA & $\mathrm{C}_{10} \mathrm{H}_{13} \mathrm{NO}_{5} \mathrm{~S}$ & 259.05144 & $258.0441[\mathrm{M}-\mathrm{H}]^{-}$ & 7.58 & not previously reported, but postulated \\
\hline
\end{tabular}




\subsection{Identification of Furan-Derived Metabolites}

In previous studies by our group, the metabolites lysine-BDA (Lys-BDA), acetyl lysine-BDA (AcLys-BDA), and glutathione-BDA (GSH-BDA) were identified and quantified in samples of urine collected from the participants at various times after coffee intake [20]. The resulting kinetics are shown in Figure 1.

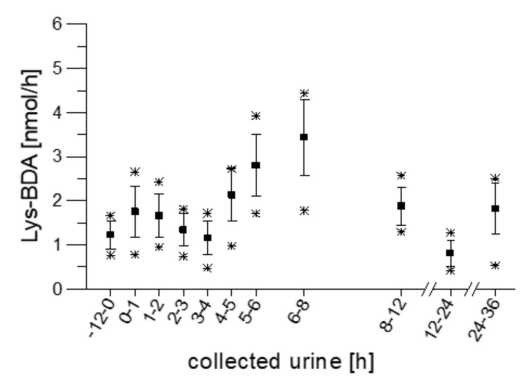

(a)

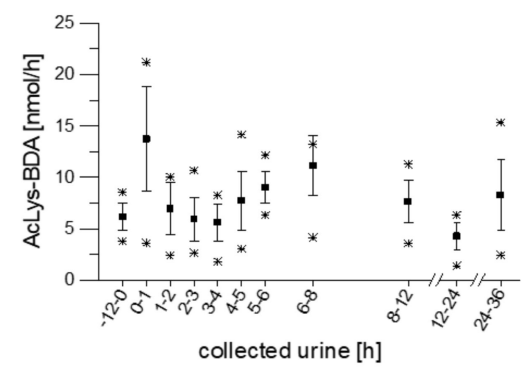

(b)

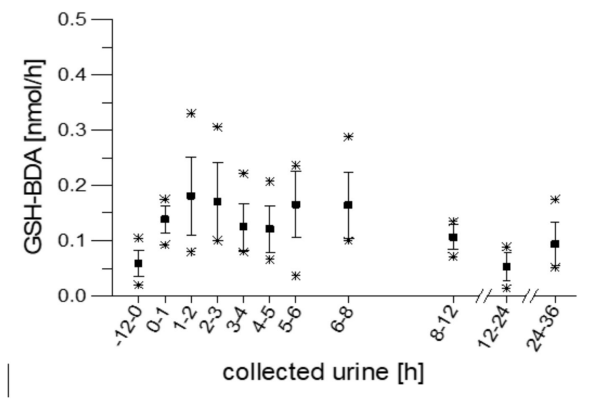

(c)

Figure 1. Excretion kinetics of Lys-BDA (a), AcLys-BDA (b), and GSH-BDA (c): HPLC-ESI-MS/MS measurements of contents in samples of urine from participants 1 to 10 at indicated times after coffee consumption (h). Data are previously published means with standard deviations and minimum/maximum values [20].

With the UPLC-qToF-MS/MS analysis, we detected Lys-BDA, NAcLys-BDA, and BDA-GSH in at least one urine sample from each participant at each selected time point, and observed similar changes with time in their concentrations (see Figure 2).

Using UPLC-qToF-MS/MS, we were able to determine exact masses and obtained $\mathrm{MS}^{2}$-spectra for all three metabolites, which enabled us to confirm their structures. Furan-derived metabolites that have been detected in urine samples from rats after furan exposure were also detected in the urine samples of the participants using this approach. These included acetylcysteine butendial lysine (AcCys-BDA-Lys), acetylcysteine-SO-butendial acetyllysine (AcCys-(SO)-BDA-AcLys), methanethiol butendial glutamic acid (methanethiol-BDA-Glu), glutathione butendial lysine (GSH-BDA-Lys), and glutathione butendial glutamine (GSH-BDA-Gln). The metabolites AcCys-BDA-Lys and AcCys-(SO)-BDA-AcLys have already been detected in urine from smokers [23] but could not be quantified in the cited study as the signals were below the respective limits of quantification (LOQs). In the study presented here, we identified both metabolites by exact masses and $\mathrm{MS}^{2}$ spectra, and obtained semi-quantitative kinetics, which correlated with the coffee intake, for the two metabolites in the urine samples of five participants (numbers three to six and eight; as shown in Figures 3 and 4). 


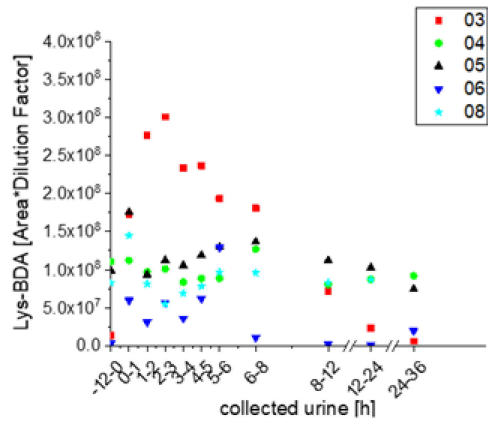

(a)

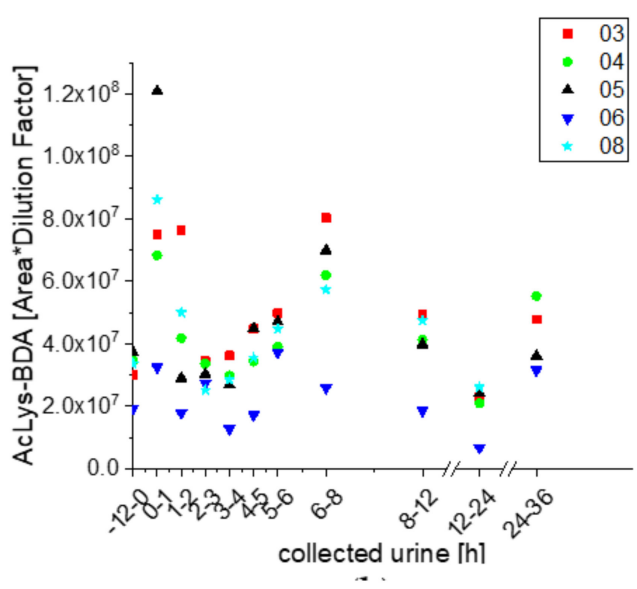

(b)

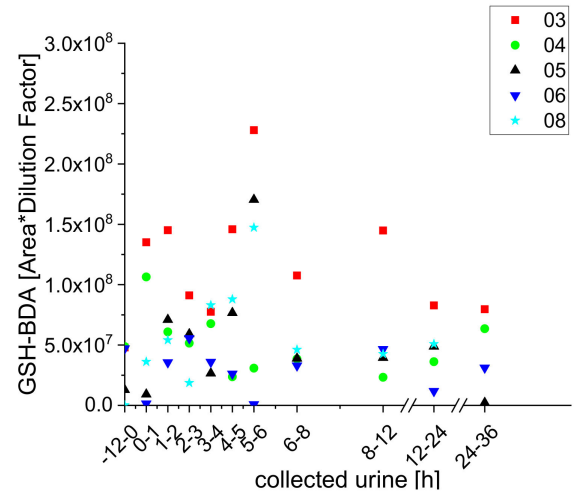

(c)

Figure 2. Excretion kinetics of Lys-BDA (a), AcLys-BDA (b), and GSH-BDA (c): UPLC-qToF-MS/MS measurements (as detailed in Materials and Methods) of contents in samples of urine from participants three, four, five, six, and eight at indicated times after coffee consumption (h). Excretion kinetics of Lys-BDA, AcLys-BDA, and GSH-BDA measured by UPLC-qToF (details see Materials and Methods section) over $36 \mathrm{~h}$ after coffee consumption. Shown are the individual kinetics of the participants three, four, five, six, and eight. The measurements were performed as triplicates and the data points are shown as mean values with standard deviation.

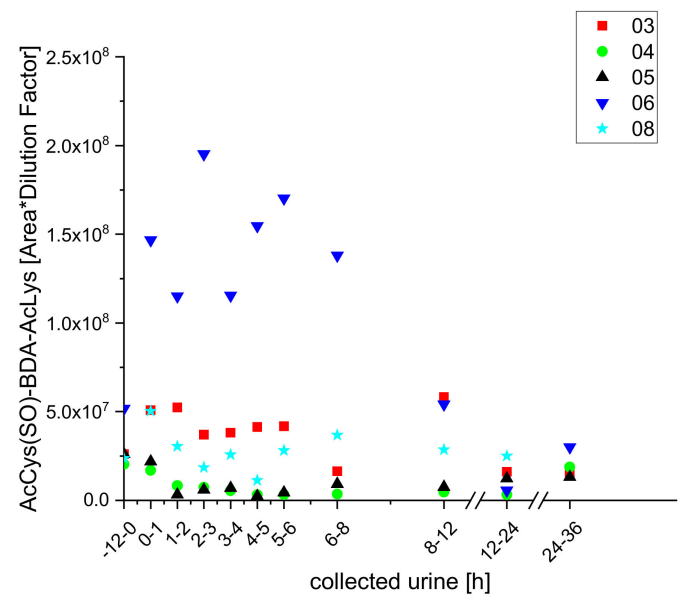

Figure 3. Excretion kinetics of AcCys-(SO)-BDA-AcLys (Rt = $4.46 \mathrm{~min}$ ): UPLC-qToF-MS/MS measurements (as detailed in Section 3) of contents in samples of urine from participants three, four, five, six, and eight at indicated times after coffee consumption (h). 


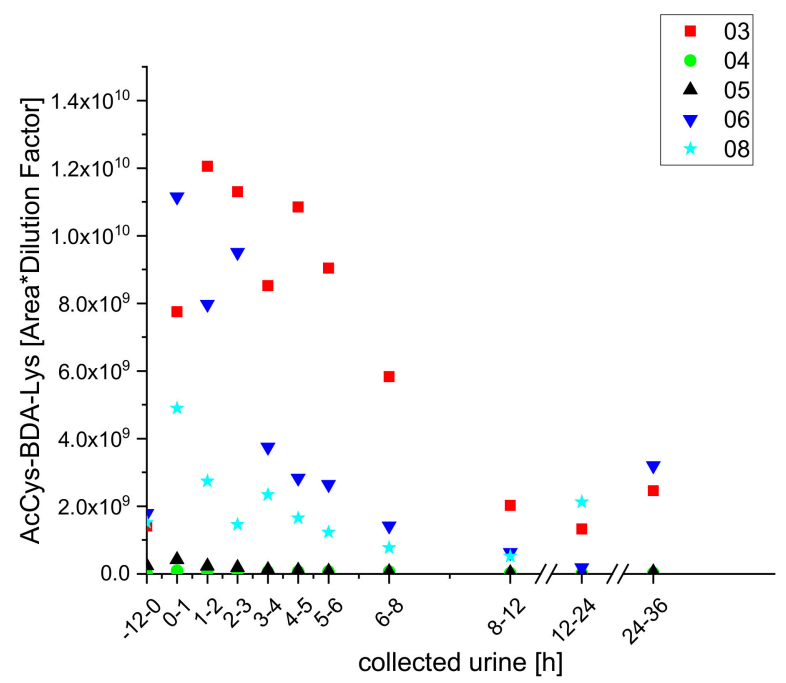

Figure 4. Excretion kinetics of AcCys-BDA-AcLys: UPLC-qToF-MS/MS measurements of contents in samples of urine from participants three, four, five, six, and eight at indicated times after coffee consumption (h).

Both AcCys-(SO)-BDA-AcLys and AcCys-BDA-AcLys were identified in samples from each of the five subjects included in the study presented here but the excretion kinetics differed, so excretion kinetic data for each individual are displayed rather than mean values for all five subjects.

The metabolite methanethiol-BDA-Glu has also been previously detected in rat urine [19] and we detected it in the urine of some of our participants but at lower levels than the other identified metabolites (too low to establish excretion kinetics).

However, we did detect two GSH-conjugates (GSH-BDA-Lys and GSH-BDA-Gln) that have been previously detected in hepatocytes and rat urine $[19,25]$ and obtained semi-quantitative kinetics for them (Figures 5 and 6).

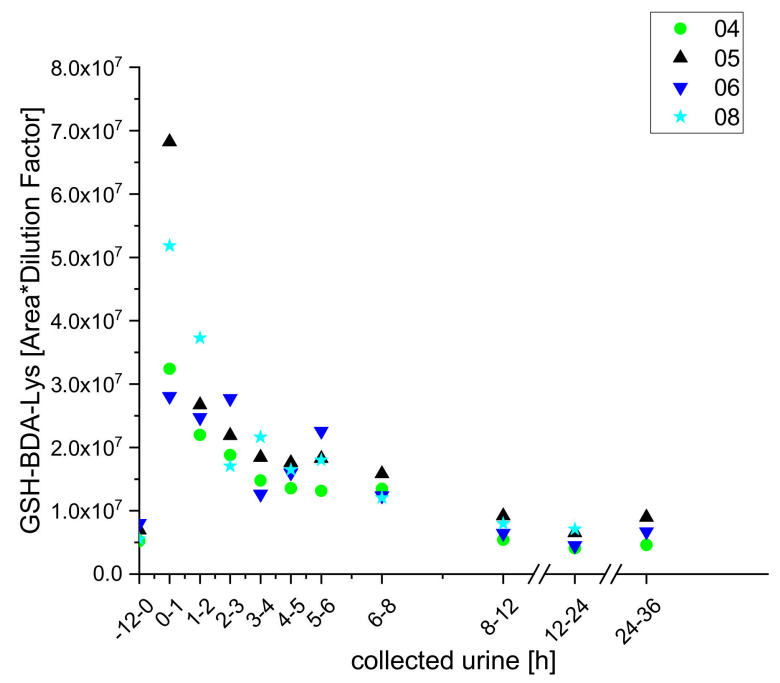

Figure 5. Excretion kinetics of GSH-BDA-Lys: UPLC-qToF-MS/MS measurements of contents in samples of urine from participants four, five, six, and eight at indicated times after coffee consumption (h).

Using UPLC-qToF-MS/MS, we also identified furan metabolites in the urine of the participants that had previously only been detected in vitro or in the bile of rats [19]. These included the GSH adducts glutathione butendial acetyl lysine (GSH-BDA-AcLys), glutathione butendial glutamic acid (GSH-BDA-Glu) cysteine butendial glutathione (Cys-BDA-GSH), and cysteine glycine butendial glutathione (Cys-Gly-BDA-GSH). All of these were identified, by exact masses and $\mathrm{MS}^{2}$ spectra, 
for the first time in urine samples of human subjects, and coffee consumption-dependent kinetics were observed for two of them (GSH-BDA-AcLys and CysGly-BDA-GSH), as shown in Figures 7 and 8.

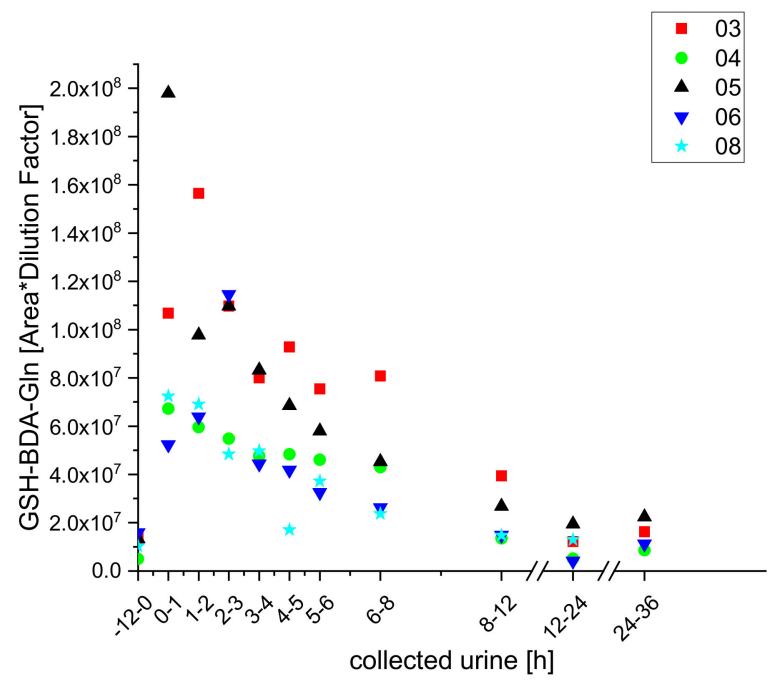

Figure 6. Excretion kinetics of GSH-BDA-Gln: UPLC-qToF-MS/MS measurements of contents in samples of urine from participants three, four, five, six, and eight at indicated times after coffee consumption (h). Excretion kinetics of the GSH-conjugate GSH-BDS-Lys from all five subjects were similar: in all cases, levels in the urine samples increased to a maximum within the first hour then continuously decreased until they reached the initial baseline level after $24 \mathrm{~h}$. In contrast, there were clear between-individual differences in excretion kinetics of GSH-BDA-Gln. Levels of this metabolite peaked in urine from subjects four and eight within the first hour, but only after $3 \mathrm{~h}$ in urine from subjects five and six. Moreover, it was not detected at all in urine from participant three.

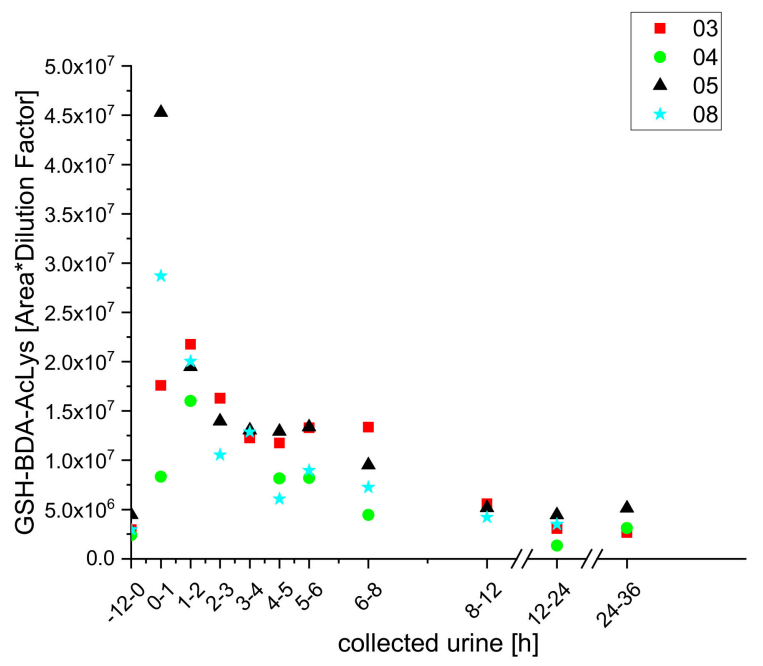

Figure 7. Excretion kinetics of GSH-BDA-AcLys: UPLC-qToF-MS/MS measurements of contents in samples of urine from participants three, four, five, and eight at indicated times after coffee consumption (h).

For GSH-BDA-Ac-Lys, we obtained similar initial values (in urine samples collected during the $12 \mathrm{~h}$ before coffee consumption) for all subjects. Moreover, its levels peaked in samples from all participants within the two hours following coffee consumption and declined to the baseline level within $24 \mathrm{~h}$. 
However, there was large variation in the triplicate determinations for samples from participant 6 , due to low concentrations of the metabolite, and high uncertainties, so we excluded these data from further analysis.

Furthermore, we identified metabolites in our urine samples, which have not been previously described in the literature at all: a biadduct of BDA with lysine (BDA-Lys-BDA) and a BDA cysteine adduct (Cys-BDA). Levels of the BDA biadduct were clearly related to the coffee intake (Figure 9).

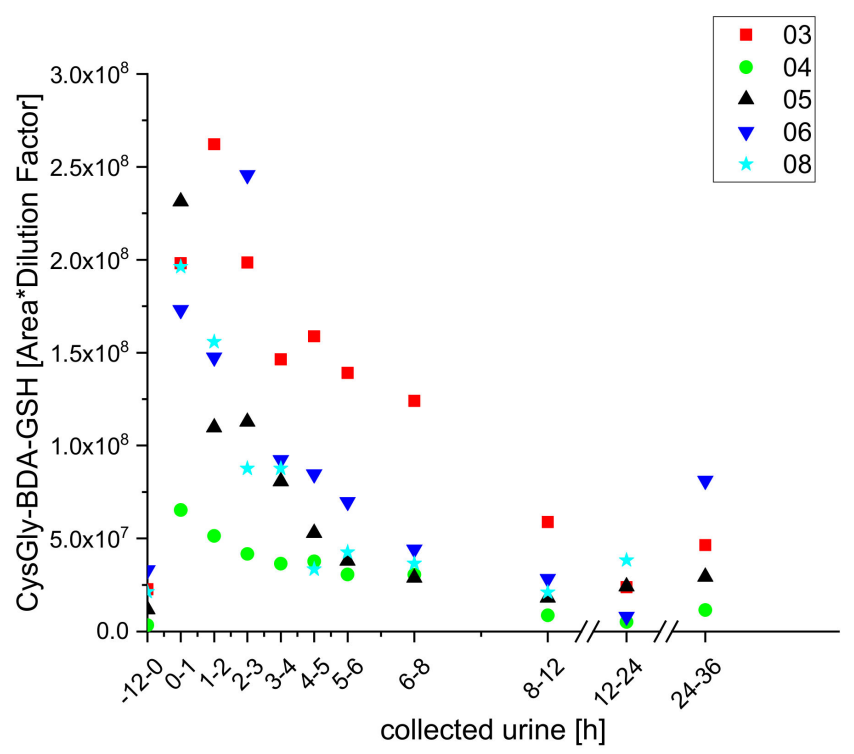

Figure 8. Excretion kinetics of CysGly-BDA-GSH: UPLC-qToF-MS/MS measurements of contents in samples of urine from participants three, four, five, six, and eight at indicated times after coffee consumption (h).

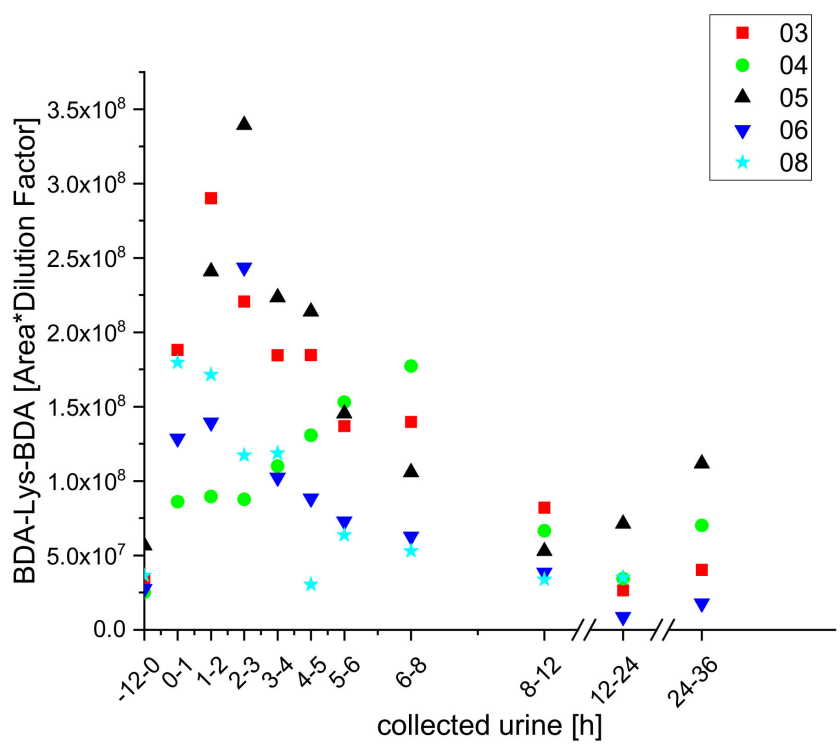

Figure 9. Excretion kinetics of BDA-Lys-BDA: UPLC-qToF-MS/MS measurements of contents in samples of urine from participants three, four, five, six, and eight at indicated times after coffee consumption (h).

Based on our findings regarding metabolites detected by the UPLC-qToF-MS/MS approach in human urine samples, we propose the metabolic pathways for furan taken in by the ingestion of a coffee brew shown in Figure 10. 


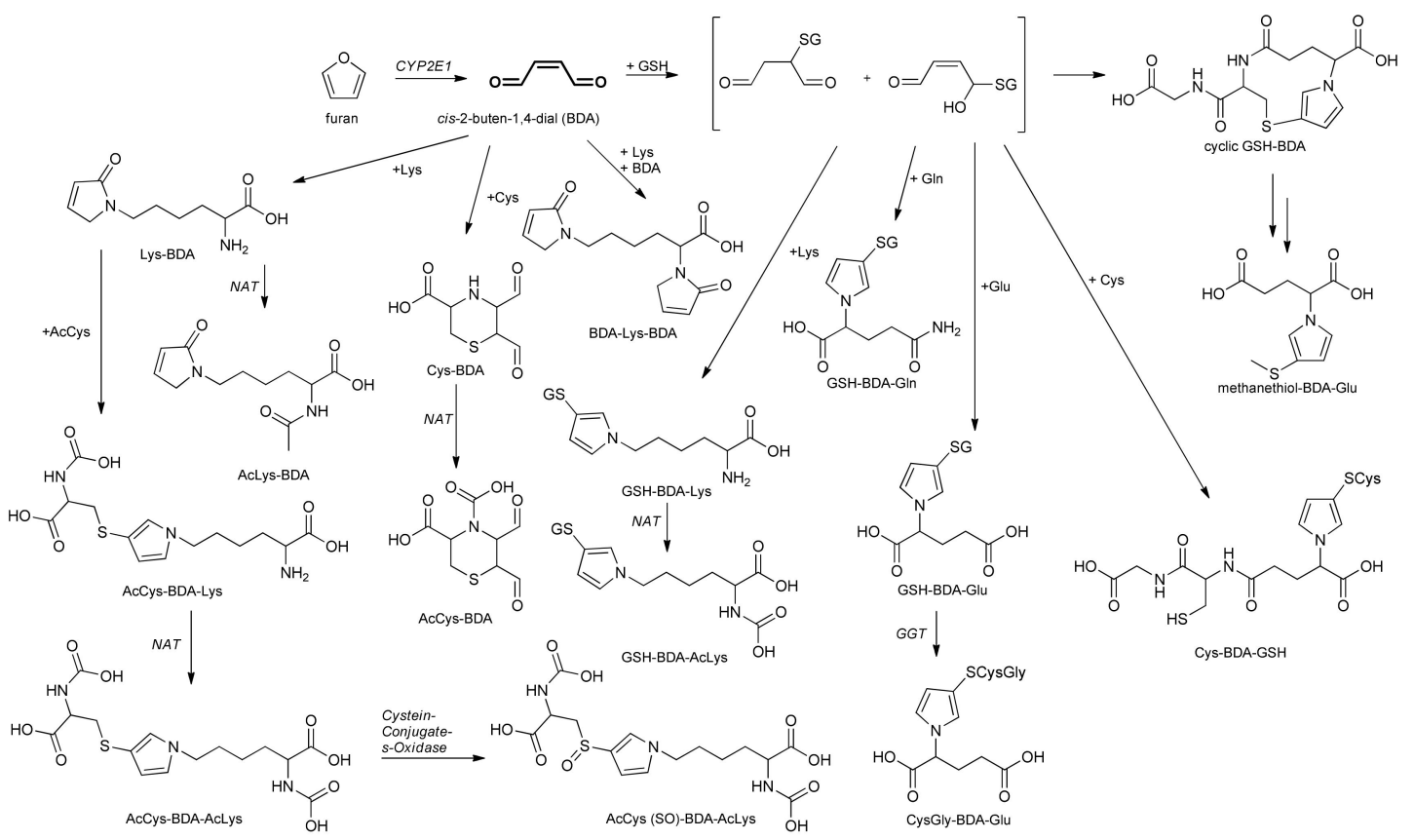

Figure 10. Proposed metabolic pathways for furan based on metabolites identified by UPLC-qToF-MS/MS in samples of urine from human participants after consumption of a bolus of coffee brew and previously identified pathways [19].

\subsection{Identification of 2-Methylfuran Derived Metabolites}

In analogy to the furan metabolites, we detected two 2-methylfuran conjugates with lysine (Lys-AcA) and acetyl lysine (AcLys-AcA) in samples of urine from the test subjects after coffee brew intake (Figures 11 and 12).

To our surprise, we also identified a conjugate of AcA and acetylcysteine, acetylcysteine acetylacrolein (AcCys-AcA), which has only been previously postulated as a theoretical metabolite, and observed kinetic changes in its levels that were strongly dependent on coffee consumption (Figure 13).

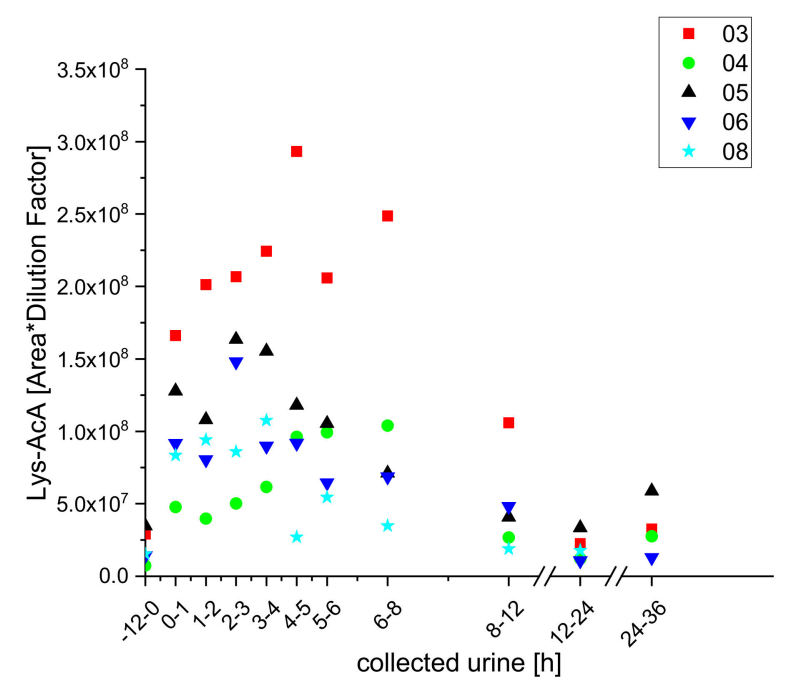

Figure 11. Excretion kinetics of Lys-AcA: UPLC-qToF-MS/MS measurements of contents in samples of urine from participants three, four, five, six, and eight at indicated times after coffee consumption (h). 


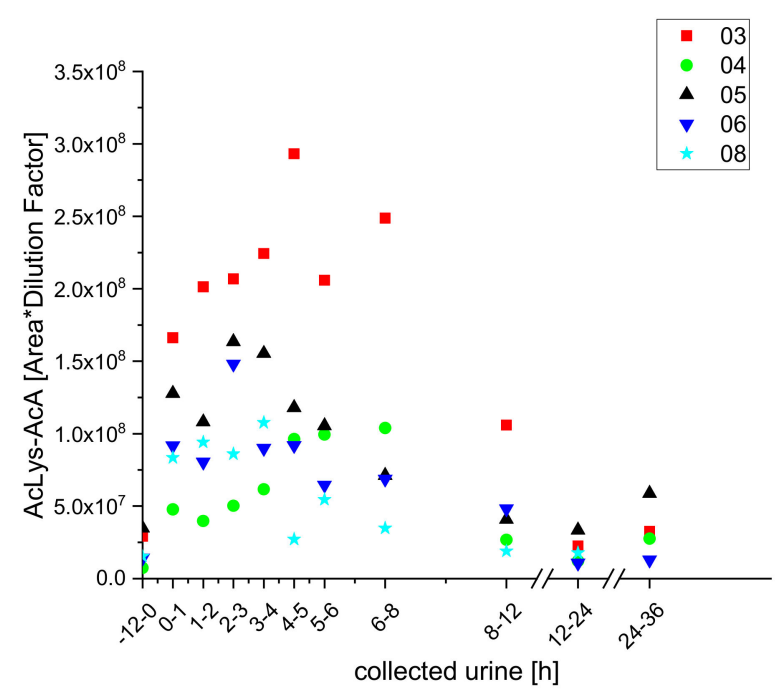

Figure 12. Excretion kinetics of AcLys-AcA: UPLC-qToF-MS/MS measurements of contents in samples of urine from participants three, four, five, six, and eight at indicated times after coffee consumption (h).

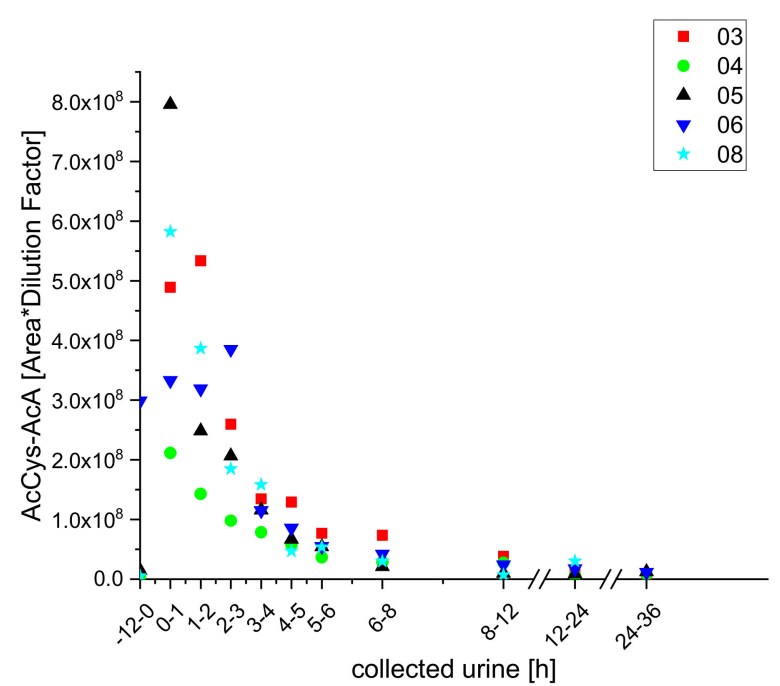

Figure 13. Excretion kinetics of AcCy-AcA: UPLC-qToF-MS/MS measurements of contents in samples of urine from participants three, four, five, six, and eight at indicated times after coffee consumption (h).

\section{Materials and Methods}

\subsection{Chemicals and Reagents}

Acetonitrile and formic acid (both LC-MS grade) were purchased from Honeywell (Charlotte, North Carolina, USA), and Biosolve (Valkenswaard, The Netherlands), respectively. Double distilled water produced with a BÜCHI (Essen, Germany) unit was used for the solvents and to dilute the urine samples.

\subsection{Human Urine Samples}

The analyzed urine specimens were obtained in a previously described human intervention study [17]. The study, which was approved by the ethical committee of the Rhineland-Palatinate medical commission (Approval No. 837.427.15(10195)) was performed in accordance with ethical standards of the Declaration of Helsinki (1964) [27]. For the exploratory investigation presented here, samples from five of the 10 subjects were examined. Portions of urine samples collected at time points 
indicated in the figures were membrane-filtered, transferred to autosampler vials, and subjected to UPLC-qToF-MS/MS analyses.

\subsection{Liquid Chromatography-High Resolution Mass Spectrometry (LC-HRMS)}

The urine samples were analyzed using a ExionLC ${ }^{\mathrm{TM}}$ AD System (Darmstadt, Germany) coupled with a TripleTOF ${ }^{\circledR} 6600$ system from Sciex. The UPLC conditions were chosen to detect the broadest possible range of metabolites. They were separated using a Synergi 4 u polar RP column $(100 \times 2.00 \mathrm{~mm}$, Phenomenex, Torrance, CA, USA) with a column oven temperature of $20^{\circ} \mathrm{C}$ and a mobile phase consisting of a mixture of $0.1 \%$ aqueous formic acid (A) and acetonitrile (B): $1 \%$ B for 0.1 min, linear increases to $30 \%$ B from 0.1 to $5.8 \mathrm{~min}$, then to $80 \% \mathrm{~B}$ within $0.1 \mathrm{~min}$, followed by a hold of $80 \% \mathrm{~B}$ for $2 \mathrm{~min}$ and re-equilibration to $1 \% \mathrm{~B}$ for a further $2 \mathrm{~min}$ (with a constant flow rate of $300 \mu \mathrm{l} \mathrm{min}{ }^{-1}$ ). Eluting analytes were quantified by the MS system operating in both positive and negative ionization modes. The conditions for positive mode were: curtain gas (CUR) $30 \mathrm{psi}$, ion source gas (GS) 1 and 2 pressure 60 and $70 \mathrm{psi}$, temperature $500{ }^{\circ} \mathrm{C}$, ion spray voltage floating (ISVF) $5000 \mathrm{~V}$. Conditions for negative mode were: CUR $40 \mathrm{psi}$, GS 1 and 2 pressure 60 and $70 \mathrm{psi}$, temperature $650{ }^{\circ} \mathrm{C}$, ISVF $4000 \mathrm{~V}$. First acquisitions of mass spectra were performed using positive and negative ionization modes with information-dependent acquisition (IDA) of product ions. In full-scan mode, the accumulation time was $100 \mathrm{~ms}$ for a mass range from 60 to $800 \mathrm{Da}$. Each IDA experiment had an accumulation time of $60 \mathrm{~ms}$ with the collision energy set to -35 or $35 \mathrm{eV}$ with a spread of $15 \mathrm{eV}$ in high-resolution mode. The IDA criteria were as follows: the 15 most intense ions (number of IDA experiments) with an intensity threshold of $200 \mathrm{cps}$ and exclusion time of $5 \mathrm{~s}$ after one occurrence. In second acquisitions, spectra were acquired data-independently by the "sequential window acquisition of all theoretical fragment-ion spectra" (SWATH $\left.{ }^{\circledR}\right)$ method with positive and negative ionization. Here the full scans also covered the 60 to $800 \mathrm{Da}$ range with -10 and $10 \mathrm{eV}$ collision energy and an acquisition time of $150 \mathrm{~ms}$. Generally, the IDA data were used to identify the metabolites, but for those for which no MS ${ }^{2}$ spectra were included in the IDA acquisition, the SWATH data were used.

The UPLC-qToF-System was controlled by Analyst ${ }^{\circledR}$ TF Software 1.7 (AB Sciex Pte. Ltd, Singapore) and the data were analyzed with Sciex OS 1.5.0.23389 (AB Sciex Pte. Ltd, Singapore/), MetabolitePilote ${ }^{\mathrm{TM}}$ v. 2.0 (AB Sciex Pte. Ltd, Singapore), and MarkerView ${ }^{\mathrm{TM}}$ v. 1.3.1 software (AB Sciex Pte. Ltd, Singapore).

\subsection{Data Evaluation and Illustration}

The data obtained from the IDA measurements were processed as follows.

To determine excretion kinetics of the detected metabolites, the peak areas obtained from the TOF-MS measurements were normalized with respect to the weights of the corresponding urine samples and plotted, in the form of area times dilution factor $(\mathrm{y})$ values, against the time points when the samples were collected after coffee intake ( $x$ values, in hours).

The obtained kinetics of the single metabolites are semi-quantitative or relative evaluations because no standards were included in the measurements, which would have allowed determination of concentrations of the single metabolites.

Exact masses were assigned to the individual metabolites using the $\mathrm{MS}^{2}$ spectra obtained, in conjunction with published data and spectral predictions. The SWATH data were used if no $\mathrm{MS}^{2}$ spectrum of the metabolites was included in the IDA data. The recorded MS² spectra and the assignment of the fragments are shown in the Supplementary Materials.

The metabolites were searched for using a library in SciexOS based on the structures and masses known in the literature and on the other hand masses were extracted, which showed a significant difference between the first two points in time. Furthermore, for 2-MF derived adducts analogous reactions as for furan were assumed and explicitly searched for this. 


\section{Conclusions}

The presented results show that the UPLC-qToF-MS/MS approach can identify metabolites in a complex matrix such as urine rapidly and robustly without extensive sample preparation. Using it, we identified both metabolites that have already been identified in human urine samples and others that have only been previously detected in animal studies or theoretically postulated. Moreover, we obtained information on the excretion kinetics of $x$ identified metabolites following the single intake of a coffee brew, and kinetics observed for y metabolites matched those obtained in previous targeted analyses.

Although these data provide a good overview of furan and 2-MF metabolites excreted in urine after the intake of a coffee brew, the study has several limitations. Quantification of the metabolites, and thus balancing of the total excretion of the furan and 2-methylfuran taken in from a coffee brew, is almost impossible with the available data, and at least one standard compound would have to be added to the samples for calibrated quantification. In addition, the subjects' drinking behavior, and thus their urine volumes, varied substantially. Standardization of the urine's dilution factors, e.g., using creatinine concentrations, would be helpful for enhancing the approach.

In summary, the new UPLC-qToF-MS/MS approach has several advantages that the targeted analysis of metabolites in a complex matrix such as urine lacks. If the analytical goal is considered when acquiring the samples, it can potentially provide abundant additional information in future animal or human intervention studies. The opportunities it provides for statistical evaluation of the data and rapid identification of metabolites responsible for differences in kinetic profiles of samples may be particularly valuable.

Supplementary Materials: The following materials are available online: Figure S1: MS/MS spectrum of Lys-BDA; Figure S2: MS/MS spectrum of AcLys-BDA; Figure S3: MS/MS spectrum of GSH-BDA; Figure S4: MS/MS spectrum of AcCys(SO)-BDA-AcLys; Figure S5: MS/MS spectrum of AcCys-BDA-Lys; Figure S6: MS/MS spectrum of GSH-BDA-Lys; Figure S7: MS/MS spectrum of GSH-BDA-Gln; Figure S8: MS/MS spectrum of GSH-BDA-AcLys; Figure S9: MS/MS spectrum of CysGly-BDA-GSH; Figure S10: MS/MS spectrum of BDA-Lys-BDA; Figure S11: MS/MS spectrum of Lys-AcA; Figure S12: MS/MS spectrum of AcLys-AcA; Figure S13: MS/MS spectrum of AcCys-AcA; Figure S14: Urinary metabolites of 2-methylfuran.

Author Contributions: Conceptualization, E.R.; methodology, S.S., C.B., D.M., and J.I.K.; software, C.B., N.B., S.S., and D.M.; investigation, S.S.; data curation, N.B. and S.S.; project administration, E.R.; resources, E.R.; writing-original draft preparation, S.S., E.R., and N.B.; writing-review and editing, E.R., J.I.K., N.B., and S.S.; visualization, N.B.; formal analysis, S.S.; validation, S.S., J.I.K., and N.B.; supervision, E.R. All authors have read and agreed to the published version of the manuscript.

Funding: No external funding was received for this research.

Acknowledgments: We thank the volunteers for their participation, and Tamara Bakuradze for her support in the human intervention study.

Conflicts of Interest: The authors declare no conflict of interest.

\section{References}

1. IARC. Dry Cleaning, Some Chlorinated Solvents and Other Industrial Chemicals; International Agency for Research on Cancer: Lyon, France, 1995; ISBN 978-92-832-1563-9.

2. National Center for Biotechnology Information. 2-Methylfuran. Available online: https://pubchem.ncbi.nlm. nih.gov/compound/2-methylfuran (accessed on 23 March 2020).

3. European Food Safety Authority. Update of results on the monitoring of furan levels in food. EFSA J. 2010, 8, 1702. [CrossRef]

4. Altaki, M.; Santos, F.J.; Galceran, M. Occurrence of furan in coffee from Spanish market: Contribution of brewing and roasting. Food Chem. 2011, 126, 1527-1532. [CrossRef]

5. Fromberg, A.; Fagt, S.; Granby, K. Furan in heat processed food products including home cooked food products and ready-to-eat products. EFSA Support. Publ. 2009, 6. [CrossRef]

6. Knutsen, H.K.; Alexander, J.; Barregård, L.; Bignami, M.; Brüschweiler, B.; Ceccatelli, S.; Cottrill, B.; Dinovi, M.; Edler, L.; Grasl-Kraupp, B.; et al. Risks for public health related to the presence of furan and methylfurans in food. EFS2 2017, 15. [CrossRef] 
7. Locas, C.P.; Yaylayan, V.A. Origin and mechanistic pathways of formation of the parent furan-A food toxicant. J. Agric. Food Chem. 2004, 52, 6830-6836. [CrossRef]

8. Limacher, A.; Kerler, J.; Davidek, T.; Schmalzried, F.; Blank, I. Formation of furan and methylfuran by maillard-type reactions in model systems and Food. J. Agric. Food Chem. 2008, 56, 3639-3647. [CrossRef]

9. Adams, A.; Bouckaert, C.; Van Lancker, F.; De Meulenaer, B.; De Kimpe, N. Amino acid catalysis of 2-alkylfuran formation from lipid oxidation-derived $\alpha, \beta$-unsaturated aldehydes. J. Agric. Food Chem. 2011, 59, 11058-11062. [CrossRef]

10. Neuwirth, C.; Mosesso, P.; Pepe, G.; Fiore, M.; Malfatti, M.; Turteltaub, K.; Dekant, W.; Mally, A. Furan carcinogenicity: DNA binding and genotoxicity of furan in rats in vivo. Mol. Nutr. Food Res. 2012, 56, 1363-1374. [CrossRef]

11. National Toxicology Program. Toxicology and Carcinogenesis Studies of Furan (CAS No. 110-00-9) in F344 rats and B6C3F1 mice (gavage studies). Natl. Toxicol. Program Tech. Rep. Ser. 1993, 402, 1-286.

12. De Conti, A.; Kobets, T.; Escudero-Lourdes, C.; Montgomery, B.; Tryndyak, V.P.; Beland, F.A.; Doerge, D.R.; Pogribny, I.P. Dose- and time-dependent epigenetic changes in the livers of fisher 344 rats exposed to furan. Toxicol. Sci. 2014, 139, 371-380. [CrossRef]

13. Peterson, L.A.; Naruko, K.C.; Predecki, D.P. A Reactive metabolite of furan,cis-2-butene-1,4-dial, is mutagenic in the ames assay. Chem. Res. Toxicol. 2000, 13, 531-534. [CrossRef]

14. Palmen, N.; Evelo, C.T. Glutathione depletion in human erythrocytes and rat liver: A study on the interplay between bioactivation and inactivation functions of liver and blood. Toxicol. Vitr. 1996, 10, 273-281. [CrossRef]

15. Ravindranath, V.; Burka, L.; Boyd, M. Reactive metabolites from the bioactivation of toxic methylfurans. Science 1984, 224, 884-886. [CrossRef]

16. Gill, S.S.; Kavanagh, M.; Cherry, W.; Barker, M.; Weld, M.; Cooke, G.M. A 28-day Gavage Toxicity Study in Male Fischer 344 Rats with 2-methylfuran. Toxicol. Pathol. 2013, 42, 352-360. [CrossRef] [PubMed]

17. Kremer, J.I.; Gömpel, K.; Bakuradze, T.; Eisenbrand, G.; Richling, E. Urinary excretion of niacin metabolites in humans after coffee consumption. Mol. Nutr. Food Res. 2018, 62, e1700735. [CrossRef]

18. Kremer, J.I.; Pickard, S.; Stadlmair, L.F.; Glaß-Theis, A.; Buckel, L.; Bakuradze, T.; Eisenbrand, G.; Richling, E. Alkylpyrazines from coffee are extensively metabolized to pyrazine carboxylic acids in the human body. Mol. Nutr. Food Res. 2019, 63, e1801341. [CrossRef]

19. Moro, S.; Chipman, J.K.; Wegener, J.W.; Hamberger, C.; Dekant, W.; Mally, A. Furan in heat-treated foods: Formation, exposure, toxicity, and aspects of risk assessment. Mol. Nutr. Food Res. 2012, 56, 1197-1211. [CrossRef]

20. Kremer, J.I.; Karlstetter, D.; Klier, C.; Rohtermund, J.; Thomas, H.; Becker, H.; Lang, L.; Bakuradze, T.; Eisenbrand, G.; Richling, E. Detection and stability of BDA-lysine and -glutathione metabolites as urinary exposure biomarkers for furan in humans. Naunyn-Schmiedebergs Arch. Pharmacol. 2020, 393 (Suppl. 1), S1-S97. [CrossRef]

21. Peterson, L.A.; Cummings, M.E.; Chan, J.Y.; Vu, C.C.; Matter, B.A. Identification of acis-2-butene-1,4-dial-derived glutathione conjugate in the urine of furan-treated rats. Chem. Res. Toxicol. 2006, 19, 1138-1141. [CrossRef]

22. Lu, D.; Sullivan, M.M.; Phillips, M.B.; Peterson, L.A. Degraded protein adducts ofcis-2-butene-1,4-dial are urinary and hepatocyte metabolites of furan. Chem. Res. Toxicol. 2009, 22, 997-1007. [CrossRef]

23. Grill, A.E.; Schmitt, T.; Gates, L.A.; Lu, D.; Bandyopadhyay, D.; Yuan, J.M.; Murphy, S.E.; Peterson, L.A. Abundant rodent furan-derived urinary metabolites are associated with tobacco smoke exposure in humans. Chem. Res. Toxicol. 2015, 28, 1508-1516. [CrossRef] [PubMed]

24. Kellert, M.; Wagner, S.; Lutz, U.; Lutz, W.K. Biomarkers of furan exposure by metabolic profiling of rat urine with liquid chromatography-tandem mass spectrometry and principal component analysis. Chem. Res. Toxicol. 2008, 21, 761-768. [CrossRef] [PubMed]

25. Rietjens, I.M.C.M.; Recker, T.; Günther, H.; Hanlon, P.; Honda, H.; Mally, A.; O’Hagan, S.; Scholz, G.; Seidel, A.; Swenberg, J.; et al. Exposure assessment of process-related contaminants in food by biomarker monitoring. Arch. Toxicol. 2018, 92, 15-40. [CrossRef] [PubMed] 
26. Hamberger, C.; Kellert, M.; Schauer, U.M.; Dekant, W.; Mally, A. Hepatobiliary toxicity of furan: Identification of furan metabolites in bile of male F344/N rats. Drug Metab. Dispos. 2010, 38, 1698-1706. [CrossRef]

27. World Medical Association. WMA Declaration of Helsinki: Ethical Principles for Medical Research Involving Human Subjects. Available online: https:/www.wma.net/policies-post/wma-declaration-of-helsinki-ethicalprinciples-for-medical-research-involving-human-subjects/ (accessed on 18 September 2020).

Publisher's Note: MDPI stays neutral with regard to jurisdictional claims in published maps and institutional affiliations.

(C) 2020 by the authors. Licensee MDPI, Basel, Switzerland. This article is an open access article distributed under the terms and conditions of the Creative Commons Attribution (CC BY) license (http://creativecommons.org/licenses/by/4.0/). 